\title{
O PROJETO DE CURSO EM DEBATE A PARTIR DE FALAS DE PROFESSORES DA LICENCIATURA EM ESPANHOL DO INSTITUTO FEDERAL DE BRASÍLIA ${ }^{1}$
}

\section{THE COURSE PROJECT IN DEBATE FROM THE SPEECHES OF TEACHERS OF SPANISH DEGREES AT THE INSTITUTO FEDERAL DE BRASÍLIA}

\author{
Antonio Ferreira da Silva Júnior* \\ Gretel Eres Fernández ${ }^{* *}$
}

\begin{abstract}
Resumo: Neste artigo refletimos sobre os cursos de Licenciatura em Letras/Espanhol nos Institutos Federais como uma política de expansão do ensino superior brasileiro (OTRANTO, 2010, 2013; SILVA JÚNIOR, 2016). Para isso, empregamos o grupo de discussão como estratégia metodológica para pensar o projeto de curso do Instituto Federal de Brasília (IFB), tomado como recorte. Escutamos os sujeitos e analisamos suas falas para levantar imagens de docência predominantes em suas concepções de trabalho. Definimos o grupo de discussão (ARANTES; DEUSDARÁ, 2017; GATTI, 2012) como importante procedimento e instrumento de geração de dados sobre formação de professores, tornando os participantes peças fundamentais do processo histórico de implantação e continuidade do curso em pauta. Os dados gerados revelam sentidos construídos para a inserção dessa Licenciatura no IFB, a contratação de professores formadores, a pouca experiência dos docentes no ensino superior e concepções de trabalho com a língua no projeto de curso.
\end{abstract}

Palavras-chave: Licenciatura. Grupo de discussão. Falas. Formação de professores. Língua espanhola.

\begin{abstract}
In this article we reflect on the degree courses in Spanish Letters at the Federal Institutes as an expansion policy of Brazilian higher education (OTRANTO, 2010, 2013; SILVA JÚNIOR, 2016). For this, we used the discussion group as a methodological strategy to think about the course project of the Instituto Federal de Brasilia (IFB) taken as a methodological approach. We listened to the subjects and analyzed the speeches to raise images of teaching predominant in their work conceptions. We define the discussion group (ARANTES; DEUSDARÁ, 2017; GATTI, 2012) as an important procedure and instrument for generating data on teacher training, making the participants fundamental parts of the historical process of implementation and continuity of the course in question. The data generated reveal meanings built for the insertion of Spanish degree in the IFB, the hiring teacher trainers, the little experience of teachers in higher education and conceptions of working with the Spanish language in the course project.
\end{abstract}

Keywords: Graduation. Discussion group. Teacher training. Spanish language.

\footnotetext{
${ }^{1}$ Este artigo apresenta um recorte da pesquisa de estágio pós-doutoral intitulada "Cursos de Licenciatura em Letras/Espanhol nos Institutos Federais do Sudeste de Minas Gerais e Brasília. Experiências profissionais e perfis docentes: as narrativas como momentos de reflexão", concluída em julho de 2018 na Faculdade de Educação da Universidade de São Paulo.

* É professor de Língua Espanhola da Universidade Federal do Rio de Janeiro, atuando no Colégio de Aplicação e no Programa de Pós-Graduação em Letras Neolatinas da Faculdade de Letras. Doutor em Letras Neolatinas pela UFRJ. Pós-Doutorado em Linguística Aplicada pela PUC-SP e em Educação pela USP. E-mail: afjrespanhol@gmail.com

** É Professora da Faculdade de Educação da Universidade de São Paulo (USP). Doutora pela Faculdade de Educação da Universidade de São Paulo (USP), com Pós-Doutorado pela Universidade de Murcia, Espanha. E-mail: igmefern@usp.br
} 


\section{Introdução}

O ano de 2008 marcou na história e na política da educação profissional uma importante transformação dessa modalidade de ensino ${ }^{2}$. A reconfiguração dos Centros Federais de Tecnologia (Cefet) e escolas técnicas vinculadas às Universidades possibilitou a criação dos Institutos Federais de Educação, Ciência e Tecnologia (IFs), contribuindo para uma nova conformação do ensino médio e técnico profissionalizante e, principalmente, por ser uma instituição responsável pela formação em nível superior ${ }^{3}$. De acordo com Otranto e Paiva (2016, p. 8), temos a constituição de uma nova "arquitetura acadêmica", que visa potencializar projetos formativo-científicos para aumentar a qualidade da educação superior, Graduação e Pós-Graduação. (FRANCO; MOROSINI, 2012).

Interessados nessa oferta de cursos de Licenciatura em Letras/Espanhol nos IFs, optamos por iniciar a reflexão com uma revisão bibliográfica sobre o assunto da formação inicial no contexto da educação profissional e tecnológica. Já para pensar o trabalho de professores formadores empregamos um instrumento de geração de dados de natureza qualitativa: o grupo de discussão (GD).

Este estudo apoia-se nos pressupostos da pesquisa narrativa (TELLES, 2002) e da construção compartilhada proposta pela técnica do grupo de discussão (ARANTES; DEUSDARÁ, 2017) como recurso para o entendimento do contexto de implantação de cursos de Licenciatura em Letras/Espanhol no cenário do Instituto Federal de Brasília (IFB), selecionado para este artigo. O foco do material oral gerado recai na experiência dos professores formadores, suas reflexões sobre o trabalho docente e suas concepções de linguagem para o tema da formação de docentes e foi fundamental para compreendermos qual trabalho é desenvolvido no curso de Licenciatura e quais concepções de formação são mais difundidas pelos participantes.

Para este artigo, escolhemos o GD como procedimento metodológico e instrumento de geração de dados, porque o entendemos como uma etapa importante de pesquisa antes das entrevistas individuais com os sujeitos participantes, outra estratégia metodológica que não será problematizada neste estudo.

A opção metodológica pela modalidade qualitativa de natureza narrativa também partiu da vivência compartilhada entre o pesquisador e sujeitos participantes da pesquisa, pois, segundo Telles (2002), esse aspecto seria um ponto positivo para o entendimento do material documental a ser gerado. Os colaboradores são, portanto, docentes pertencentes à Rede Federal de Educação Profissional e Tecnológica, da qual os IFs são parte integrante, o que contribuiu para a criação de um espaço formativo e crítico-reflexivo de formação mútua.

\footnotetext{
2 Otranto (2010) apresenta o cenário tenso vivenciado pelas instituições (Centros Federais, Escolas Técnicas, Escolas Agrotécnicas e Escolas técnicas vinculadas às Universidades) que foram convidadas pelo Ministério da Educação a aderir ao projeto dos IFs. A criação dessa nova institucionalidade estava, inclusive, como meta do Plano Nacional de Educação (PNE) do governo do Presidente Lula e também era um dos eixos do Plano de Aceleração do Crescimento (PAC).

${ }^{3}$ Vale relembrar que, desde 2004, o Ministério da Educação reconheceu os Cefet como instituições de ensino superior, diferenciando-se das demais que compunham a Rede: escolas técnicas, agrotécnicas e vinculadas às Universidades. Talvez possamos dizer que os IFs originários dos Cefet tinham uma maior experiência na educação universitária.
} 
Assim o GD constituiu-se como espaço de troca de experiências no intuito reconstruir o cenário investigado, escutar as histórias de docência dos sujeitos no IFB e suas imagens para a formação de professores de espanhol nesse cenário.

A seguir, estruturamos o artigo em seções sobre a presença de cursos de Licenciaturas nos IFs, visando pensar esses espaços como lugares alternativos para essa formação; a última reforma das Licenciaturas proposta pelo Ministério da Educação (MEC), como forma de identificar a contribuição dos IFs nessa oferta; a abertura da educação profissional e tecnológica para os projetos de cursos na área de Letras; o GD como instrumento metodológico potencializador do debate sobre o trabalho do professor formador e, por último, o debate sobre o projeto de curso mediante os diálogos travados entre os participantes da etapa qualitativa da pesquisa.

\section{A oferta de cursos de Licenciatura nos Institutos Federais}

A criação dos IFs, pela Lei $n^{0}$. 11.892/08 (BRASIL, 2008), representou uma ampliação da oferta de vagas no ensino superior público federal em nosso país. Pelo texto legal, cada IF passou a disponibilizar cursos de Graduação e Pós-Graduação em diferentes áreas do conhecimento, incluindo os cursos de Licenciatura, foco de interesse deste artigo.

No Brasil, a presença das escolas técnicas secundaristas data de 1909, portanto, é anterior às Universidades Federais, que iniciaram sua missão formativa em torno de 1930. A formação em nível superior nas antigas escolas de educação profissional começa em alguns estados somente em 1960 com cursos da área tecnológica e de engenharias. No âmbito da formação inicial de professores, os primeiros cursos surgem somente a partir de 2000. Já em 2009, os IFs comemoram seu centenário, a expansão quantitativa de campi em todo o país, a ampliação da oferta de cursos e do número de matrículas (PACHECO, 2010).

Otranto (2010) reconhece a criação dos IFs como uma das políticas públicas de educação profissional mais significativa dessa modalidade e para a própria história das instituições que aderiram à proposta do governo. No entanto, a investigadora já demonstrava a necessidade de acompanhamento dessas "novas" instituições que surgiram com o compromisso de implementar cursos de ciências aplicadas. De acordo com ela,

A análise da lei [Lei de criação dos Institutos Federais] já aponta algumas ambiguidades que vêm gerando interpretações particulares. Uma delas é atribuir o significado de 'pesquisa aplicada' à pesquisa dirigida aos setores industriais e empresariais. Porém, a quantidade de finalidades e características expressas na lei, no seu artigo $6^{\circ}$, passa a certeza de que o IFET é, em última análise, mais um modelo alternativo à 'universidade de pesquisa', que vem sendo implementado na América Latina, nos últimos anos, a partir do incentivo explícito do Banco Mundial (OTRANTO, 2010, p. 101).

A citação anterior explicita os inúmeros papéis assumidos por um Instituto Federal a partir de sua criação e como essas múltiplas atribuições acabam por gerar um tipo de instituição muito próxima ao modelo alternativo de universidade apontado pelo 
Banco Mundial ${ }^{4}$ desde a década de 1990 (OTRANTO, 2013), cuja estrutura é mais flexível. Além disso, devido à expansão das áreas de conhecimento no contexto de atuação dos IF, o modelo vigente ainda não tem vivência acadêmica e de pesquisa para reconhecer investigações de natureza aplicada no âmbito das Ciências Humanas e da Linguagem, por exemplo.

Apesar de os IFs serem equiparados às Universidades Federais ${ }^{5}$, alguns deles careciam de vivência em todos os âmbitos da educação superior (ensino, pesquisa e extensão). Assim, além das novas demandas impostas pela legislação, eles também precisaram atender à Educação Básica e profissionalizante. Vale lembrar que a verticalização do ensino, decorrente da nova lei, particulariza e diferencia os IFs das demais instituições.

Apesar de os concursos públicos para docentes da educação profissional não exigirem diplomas de titulação de Pós-Graduação, a expansão da Rede possibilitou a contratação de professores com mestrado ou doutorado. Cabe ressaltar que alguns docentes ingressam no serviço público sem cursos de Licenciatura, complementação pedagógica, nem mesmo uma especialização na área educacional. Normalmente, nas áreas técnicas e de Ciências da natureza, os professores possuem somente a formação de Bacharelado nas respectivas áreas de atuação.

Em relação à atuação docente, temos em muitos IFs a verticalização também do trabalho do professor, pois esse leciona em diferentes níveis de ensino, podendo influenciar a qualidade dos cursos, projetos pedagógicos e até mesmo no desgaste pessoal do profissional. Contudo, nesse período de doze anos desde a implementação dos IFs, não temos acompanhado mudanças em relação a essa otimização do trabalho docente. Pelo contrário, tem sido comum encontrar perfis de concurso cada vez mais generalistas e amplos, de modo que o candidato aprovado lecione diferentes componentes curriculares.

Ao tomar como exemplo o perfil do docente atuante nos cursos de Licenciatura dos IFs, Otranto (2013, p. 128) aponta mais uma adversidade dessa oferta, já que:

\footnotetext{
${ }^{4}$ O Banco Mundial inicia sua atuação na área educacional na década de 1960 , priorizando o ensino técnico e o superior em sua proposta político-educacional-financeira, sendo que a percepção era a educação como formadora de mão-de-obra para a industrialização (SIQUEIRA, 2004). Para Macedo (2011), o Banco Mundial assume o papel de investidor externo em programas de educação de países subdesenvolvidos com a função de impor mudanças e reformas nos sistemas visando desenvolvimento econômico. Essa visão de atendimento ao mero mercado pode ter sido modificada, mas acabou contaminando a política educacional brasileira. Como a intenção de criação dos Institutos Federais busca a articulação com setores produtivos locais, alguns pesquisadores acreditam que os cursos ministrados pelos Institutos apresentam uma lógica de mercado e são mais flexíveis. Para Otranto (2010), isso também contribui para construir outro perfil de universidade pública no país, uma instituição diferente das "universidades de pesquisa". A estudiosa opina que esse seja um dos motivos que impossibilitou a transformação dos Cefet em universidades tecnológicas, pois “[...] A proposta delas é atuar de forma muito similar à das universidades federais, e isso não é prioridade na política de educação profissional técnica e tecnológica da atualidade. A forma como está estruturado o IFET prevê otimização dos custos, e total controle da nova instituição, o que pode acarretar uma fiscalização e um direcionamento mais eficaz na subordinação da educação por ela ministrada aos interesses do mercado". (OTRANTO, 2010, p. 103). Consideramos que contribuímos com este artigo contra a mercantilização da educação e os dados conduzem o leitor a refletir sobre o papel político dos docentes dos Institutos Federais como principais atores responsáveis pelas mudanças no projeto inicial para essas instituições.

${ }^{5}$ Isso implica que ambas as Instituições serão reguladas, avaliadas e supervisionadas pelos mesmos critérios diante do Ministério da Educação.
} 
[...] a exigência do oferecimento desses cursos não vem acompanhada da exigência de formação pedagógica dos docentes. Como consequência encontramos, hoje, vários cursos de licenciatura e de capacitação pedagógica que contam com docentes não licenciados, mesmo para lecionar as disciplinas de didática, prática de ensino ou estágio supervisionado.

A pesquisadora não especifica em qual instituição ou curso essa incoerência ocorre, mas acreditamos que essa prática seja mais recorrente em cursos de Licenciatura da área de Matemáticas e Ciências da Natureza em função da carência também de professores formadores.

Em sua pesquisa, Otranto (2013) afirma acreditar que a formação de professores proposta pelos IFs pode levar à precarização do trabalho docente e aproxima-se ao modelo tecnicista e reducionista de formação (MACEDO, 2011), que também segue a mesma linha das proposições do Banco Mundial para a capacitação desses profissionais. A pesquisadora presume o foco nos resultados por parte dos docentes formadores dos IFs e lança alguns questionamentos sobre a oferta de licenciatura fora do lócus tradicional da universidade:

Quais os reais motivos que movem o Ministério da Educação a obrigar o oferecimento de cursos de licenciatura em instituições sem corpo docente qualificado para tal e sem tradição em pesquisa na área, quando os cursos de licenciatura das universidades estão repletos de vagas ociosas? O que isso pode representar para a formação de professores do país? (OTRANTO, 2013, p. 130).

Não estamos de acordo com o pensamento da pesquisadora em associar a formação das Licenciaturas ministradas pelos IFs a uma formação positivista e tradicional, conforme já sinalizamos em parágrafos anteriores. Otranto não dispõe de dados pontuais que permitam generalizar tais afirmações, ainda mais considerando a diversidade de cursos e IFs. O MEC não propôs um deslocamento do lócus de formação de professores das Universidades para os IFs, mas sim, em nossa opinião, ampliou a oferta de vagas de Licenciatura e democratizou o acesso ao ensino superior. Cabe ressaltar que, atualmente, temos também, quantitativamente, mais campi de IFs espalhados pelo país do que de unidades de Universidades Federais.

Em relação à inquietação de Otranto sobre o que o deslocamento da formação para os IFs pode ocasionar para os próximos anos, precisamos analisar com detalhamento cada cenário em particular. Sobre dois cursos de Licenciatura em Letras/Espanhol dos IFs, Silva Júnior (2016) apontou uma perspectiva de formação coerente com as diretrizes legais do país e cursos de Licenciatura diferenciados por distintos motivos, entre eles: oferta em um espaço universitário mais semelhante ao da escola básica, maior proximidade entre corpo docente e discente, atuação do formador na Educação Básica. 


\section{Uma breve leitura do último documento de reforma das Licenciaturas}

De acordo com Dourado (2016), no tocante à reforma dos cursos de Licenciatura, a Resolução n ${ }^{0}$ 2/2015 (BRASIL, 2015) é a última proposta do MEC para revisão curricular dos cursos no país e um documento que permitiu maior autonomia universitária na criação de projetos institucionais e de cursos, porém ainda são poucos os estudos e os debates sobre as Diretrizes propostas por essa reforma embora elas sejam mais amplas e abranjam os cursos de formação inicial, formação continuada, cursos de segunda Licenciatura e cursos de complementação pedagógica. A nova proposta conduzida pelo Conselho Nacional de Educação (CNE) é tema de discussões há mais de uma década. Nesse sentido, busca-se a valorização dos profissionais que atuam na Educação Básica, bem como a reafirmação da base nacional comum para a educação superior.

Além da valorização da formação de professores da Educação Básica, a Resolução $n^{0}$ 2/2015 aponta caminhos para se pensar a carreira docente, os salários e as condições de trabalho dos profissionais da educação. A Resolução em questão também difere da reforma curricular de $2002^{6}$ em outros aspectos: altera a carga horária da formação inicial de 2.800 horas para 3.200 horas e assegura uma base comum nacional voltada para as especificidades do trabalho docente e para o ensino superior. O aspecto diferencial do documento é o tema do respeito à pluralidade cultural e à diversidade racial como elementos formadores e intrínsecos da nação e de fundamental importância na formação de professores como forma de diminuição do preconceito, da discriminação e do silenciamento de certas questões tanto no meio acadêmico como no âmbito escolar, preconizando, assim, a promoção da igualdade e o respeito ao diferente.

Segundo Dourado (2016), as novas Diretrizes apontam também para uma mudança do projeto universitário para os próximos anos e no entendimento da diversificação ${ }^{7}$ do sistema superior brasileiro. Conforme o pesquisador,

[...] as novas Diretrizes Curriculares Nacionais (DCN) enfatizam e requerem das instituições de educação superior projetos próprios de formação, por meio da necessária articulação entre Educação Básica e Superior, a serem traduzidos, de maneira articulada, no Plano de Desenvolvimento Institucional (PDI), no Projeto Pedagógico Institucional (PPI) e nos Projetos Pedagógicos de Curso (PPC) definindo, com base nas DCN, a concepção formativa e indutora de desenvolvimento institucional (DOURADO, 2016, p. 28).

O exposto anteriormente evidencia a institucionalização de projetos e o desafio de pensar uma estrutura universitária mais colaborativa, visando maior articulação de saberes, superação de dicotomias, aproximação das discussões da Graduação e PósGraduação com a Educação Básica e manutenção da autonomia universitária. Nesse aspecto, acreditamos que os IFs terão muito a contribuir nos próximos debates e

\footnotetext{
${ }^{6}$ Embora não tenha sido a primeira reforma das Licenciaturas do país, podemos dizer que foi aquela que permitiu maiores alterações no currículo. Suas diretrizes possibilitaram uma revisão na estrutura curricular dos cursos, maior articulação da teoria com a prática, ênfase da pesquisa como foco do processo de ensino-aprendizagem, articulação do estágio com os demais componentes etc.

${ }^{7}$ O pesquisador, a partir de dados do último Censo da Educação Superior, problematiza o lócus da formação docente, e ao expor onde ela ocorre não cita os IFs.
} 
estatísticas a respeito da formação docente no país, tendo em vista a experiência desses centros com a verticalização do ensino e seu compromisso com a qualidade educação em seus diferentes níveis

\section{Projeto pedagógico e a Licenciatura em Letras/Espanhol nos Institutos Federais}

Nesta seção apresentamos a inserção de um curso de Licenciatura em Letras no cenário da Rede Federal de Educação Profissional, Científica e Tecnológica e como se configura o projeto pedagógico do curso no âmbito das demandas locais em articulação com a fala de professores formadores.

Vale ressaltar que a maioria dos cursos de Licenciatura dos IFs nasceu como resposta ao atendimento de uma normatização que estabeleceu a exigência de no mínimo $20 \%$ de vagas em cursos de formação inicial de professores. Essa exigência pode ser perigosa na visão de alguns pesquisadores, porque tende ao risco da precarização do ensino, pois a formação em nível superior é um processo complexo, devendo mobilizar toda a comunidade na discussão dos projetos pedagógicos e dos currículos (BONFIM, $2004^{8}$ ). Como forma de refletir sobre tal aspecto, este artigo contribui também para compreender o trabalho docente em um curso aprovado após a implementação da política dos IFs (BRASIL, 2008) e por meio das reflexões compartilhadas por professores formadores em um GD.

Os projetos pedagógicos das Licenciaturas em Espanhol dos IFs são considerados propostas novas, porque tais cursos não vivenciaram historicamente outros modelos de formação docente e foram aprovados após a reforma das Licenciaturas de 2002 (BRASIL, 2002a; BRASIL, 2002b), favorecendo a adoção de uma formação mais próxima ao prescrito pelo documento oficial.

Consideramos que o projeto pedagógico de um curso superior deve ser entendido como um gênero importante para a definição de uma concepção coerente de formação por parte dos docentes de um curso, que atribuem sentido e ressignificam o teor de tais prescrições, e elemento norteador da discussão do perfil desejado de profissional a ser inserido no mercado de trabalho. De acordo com Vieira-Abrahão (2002, p. 62), "Qualquer programa de formação de professores [...] é construído, de forma implícita ou explícita, sobre uma concepção de ensino, concepção esta que define os procedimentos utilizados e o conteúdo desenvolvido". Pelo exposto, cada universidade precisa refletir sobre a necessidade constante de estudar o perfil de professor mais adequado à realidade escolar de sua região. Isso implica em reconhecer o projeto de curso, conforme assinala Gadotti (apud VEIGA, 2001, p. 18) como um processo dinâmico: "[...] Todo projeto supõe ruptura com o presente e promessas para o futuro".

\footnotetext{
${ }^{8}$ De acordo com Bonfim (2004), a formação inicial de professores nos Cefet não foi amplamente discutida internamente, levando à formulação de currículos tradicionais e com carga horária reduzida. Devido à pressão do MEC e da omissão em relação ao compromisso da implantação dos cursos com recursos técnicos e humanos, as Licenciaturas não contavam com quadro docente específico, acervo bibliográfico e laboratórios, além da pouca experiência na articulação de projetos de ensino, pesquisa e extensão, atividades fundamentais de uma universidade. Somente a partir de 2003, esse "corpo estranho" (BONFIM, 2004) dentro das próprias instituições começa a apresentar bons resultados nas avaliações do MEC. Diante da realidade desse momento, a pesquisadora critica a falta de interesse da Rede Federal em promover uma aproximação entre suas diferentes instituições com o intuito de solidificar uma identidade para esses cursos.
} 
Não pretendemos traçar o histórico dos cursos de Letras no Brasil, tampouco detalhar a trajetória deles na educação profissional e tecnológica por limites de páginas e por acreditar que alguns estudos já o fizeram (SILVA JÚNIOR, 2015, 2016). No caso que nos ocupa, podemos afirmar que os cursos de Licenciatura em Espanhol dos IFs iniciam sua oferta a partir do ano de 2006, sendo os pioneiros da área de Linguagens no cenário da Rede Federal, naquele momento um universo de atuação ainda muito restrito aos saberes relacionados à área industrial, à tecnologia e às exatas.

Atualmente, os cursos de Licenciatura em Espanhol existentes na Rede Federal são em número de seis: Região Nordeste (Instituto Federal do Rio Grande do Norte IFRN, campus Natal), Região Norte (Instituto Federal de Roraima - IFRR, campus Boa Vista), Região Sul (Instituto Federal do Rio Grande do Sul - IFRS, campus Restiga), na Região Centro-Oeste (Instituto Federal de Brasília - IFB, campus Ceilândia) e na Região Sudeste (Instituto Federal Sudeste de Minas Gerais - IF Sudeste MG, campus São João del Rei e no Instituto Federal de São Paulo - IFSP, campus Avaré). Conforme já mencionado, os primeiros cursos foram aprovados no ano de $2006 \mathrm{com}$ base nos respectivos estatutos dos antigos Cefets do Rio Grande do Norte e Roraima, ou seja, esses cursos apresentaram justificativas pertinentes para sua autorização. Os demais surgem em 2013 (IF Sudeste MG e IFB) e 2017 (IFRS e IFSP).

Em relação à oferta dos cursos de Licenciatura na Rede Federal, Pacheco (2010) acredita que devido o Instituto Federal apresentar uma concepção inovadora de ensino, em todos os seus níveis, a formação de professores não poderia ser diferente, ou seja, os cursos são desenhados com o intuito de romper com o modelo fragmentado de currículo e de formação profissional, aproximando o futuro professor (sempre denominado na lei e nas publicações do MEC como "trabalhador") da realidade escolar, tarefa possível no cenário da própria instituição, haja vista a oferta da Educação Básica. Segundo Pacheco (2010, p. 22), as Licenciaturas dos IFs diferem das tradicionais porque sua concepção:

[...] cria perspectivas favoráveis quando se trata da formação de professores. Na história da educação brasileira, a formação desses profissionais esteve quase sempre no plano dos projetos inacabados ou de segunda ordem, seja por falta de concepções teóricas consistentes, seja pela ausência de políticas públicas contínuas e abrangentes. A fragilidade nas ações de valorização da carreira concorre para agravar esse quadro, haja vista a grande defasagem de profissionais habilitados em determinadas áreas.

A visão de Pacheco (2010) não coloca as Licenciaturas dos IFs como superiores às das demais instituições de ensino superior. Segundo Pereira (2004), as Licenciaturas da Rede Federal se colocam "[...] ao lado de outras instituições que historicamente vêm trabalhando nesse campo como é o caso das universidades e faculdades isoladas [...] sem deixar de lado outras atribuições". Em função de sua diversidade de atuação e aproximação à Educação Básica, os IFs podem promover Licenciaturas diferenciadas, já que, muitas vezes, o docente formador do curso está lecionando simultaneamente em turmas do Ensino Médio ou Técnico. Essa experiência possibilita empregar tal vivência na reflexão de suas ações pedagógicas em sala e na formação para a docência. 


\section{Instrumento metodológico para a geração coletiva de dados no IFB}

Como já informamos, nosso objetivo está em averiguar como os professores formadores atuantes no IFB falam sobre seu trabalho no Instituto a partir da compreensão do projeto de curso da Licenciatura. Para isso, optamos por reunir docentes para dialogar sobre o assunto mediante a adoção de um instrumento coletivo de geração de dados.

O GD foi idealizado por dois motivos: primeiro para funcionar como espaço para ouvir e compartilhar saberes em coletivo com os docentes formadores atuantes no curso de Licenciatura em Letras em questão. Essa troca ocorreu no próprio IF, na cidade de Ceilândia, e possibilitou relacionar os diferentes posicionamentos pessoais e a participação do próprio pesquisador apenas como mediador do debate. O segundo porque o GD se constituiu como instrumento de dados para complementar o material autobiográfico gerado posteriormente com alguns professores formadores, cuja etapa não vamos problematizar neste texto.

O GD pauta-se em pressupostos da psicologia social e busca analisar o produto da interação entre determinado grupo e um membro moderador, podendo assumir distintos objetivos e contextos. Segundo Gatti (2012), a abordagem de trabalho com os grupos focais permite:

[...] compreender processos de construção da realidade por determinados grupos sociais, compreender práticas cotidianas, ações e reações e fatos e eventos, comportamentos e atitudes, construindo-se uma técnica importante para o conhecimento das representações, percepções, crenças, hábitos, valores, restrições, preconceitos, linguagens e simbologias prevalentes no trato de uma dada questão por pessoas que partilham alguns traços em comum, relevantes para o estudo do problema visado (GATTI, 2012, p. 11).

Portanto, o GD permitiria esclarecer e construir discussões do nosso contexto de interesse a partir da visão coletiva dos próprios sujeitos que vivenciam a realidade a ser esmiuçada no trabalho investigativo. A técnica do GD permite que temas mais complexos sejam abordados de modo mais sutil entre os participantes a partir de uma noção de compreensão de certos questionamentos e episódios. Nesse aspecto, o GD diferencia-se da entrevista narrativa individual, pois, aqui, os dilemas já são colocados em coletivo esperando a reação dos pares e uma troca de ideias sem julgamentos ${ }^{9}$. De acordo com Mariani e Medeiros (2013, p. 20), o sujeito ao assumir, individualmente, a palavra é capaz de "[...] tomar posição no sócio-histórico [...] inscrever-se subjetivamente em redes de sentidos". Com isso, percebemos também como as experiências colocadas pelos participantes do GD são passíveis de gerar intervenções sobre o contexto de produção dessas falas.

Já na perspectiva de Arantes e Deusdará (2017), os grupos focais são instrumentos que oferecem certa estruturação proposta por uma entrevista e a espontaneidade a partir da interação coletiva, proporcionando naturalidade e clareza para

\footnotetext{
9 Diferentemente do que ocorre em outros tipos de metodologias de natureza qualitativa, a pesquisa narrativa, na perspectiva de Telles (2002), não está preocupada com a instauração da verdade e de julgamentos por parte dos colaboradores da investigação. Portanto, as críticas ou os juízos de valor não estão presentes nessa forma de documentar os dados gerados na pesquisa de cunho narrativo.
} 
os dados a serem pontuados. Os pesquisadores também expõem o papel do pesquisador como aquele responsável por estimular a interação, portanto, sua presença demanda certo encorajamento ao grupo e participação ativa na observação dos posicionamentos.

Arantes e Deusdará $(2017$, p. 799$)$ retomam as três modalidades do grupo focal e suas diferenças ${ }^{10}$. Nesta pesquisa, assumimos a proposição do GD como "proposta multimétodos qualitativos", em que tal recurso dialoga necessariamente com outras fontes de geração de dados como a observação e as entrevistas. A interação desejada para o GD não parte simplesmente de perguntas e respostas, mas sim de tópicos e construções coletivas para determinadas questões a serem debatidas, multiplicando os saberes. Nosso critério para o GD foi convidar ${ }^{11}$ todos os docentes formadores interessados em colaborar com a pesquisa, submetida à análise por meio da súmula do projeto no Instituto Federal, e recortar fragmentos e tópicos constantes no projeto do curso de Letras, a partir dos objetivos gerais da pesquisa e possíveis lacunas no texto dos documentos.

Em nossa pesquisa, os objetivos foram bem definidos e explicitados aos participantes, além disso, o roteiro prévio organizado para a geração dos dados também conduzia os colaboradores para os propósitos investigativos desejados. O GD gerado foi realizado em uma sala de aula, possibilitando que os sujeitos fossem motivados pelo ambiente físico a resgatar vivências sobre o contexto da formação de professores no próprio Instituto Federal. Esses aspectos são importantes para a geração do GD, pois, conforme apontam Arantes e Deusdará (2017), a definição dos objetivos da pesquisa, o ambiente físico, os recursos empregados, o convite e a seleção dos participantes, o roteiro e o respeito aos integrantes do estudo são elementos fundamentais para a geração de dados nos grupos focais.

Considerando nossa influência nos procedimentos necessários para a geração de dados de pesquisa de cunho narrativo e como uma forma de construir confiança entre os participantes do GD, começamos com uma apresentação e narrativa pessoal para demonstrar nossas experiências, interesses e motivo de aproximação aos colegas. A proposta dessa etapa inicial foi informar sobre como surgiu a ideia da pesquisa e ajudar a reconhecer cada professor como produtor de saberes do contexto de trabalho investigado, já que todos os envolvidos no GD vivenciam e compartilham histórias um pouco semelhantes: aproximação à educação profissional, interesse pela proposta pedagógica dos IFs, experiência nula ou reduzida no ensino superior.

O roteiro do debate do GD surgiu após nossa leitura do projeto pedagógico. Algumas lacunas e dúvidas foram sendo evidenciadas no contato com o texto $\mathrm{e}$ agrupadas como tópicos ou questões. O guia proposto para o debate reunia os seguintes tópicos com temas mais gerais e específicos a partir dos objetivos propostos, seguindo as orientações de Arantes e Deusdará (2017):

\footnotetext{
${ }^{10}$ De acordo com o referencial teórico seguido pelos autores, os grupos focais podem assumir o papel de (a) autorreferentes, (b) técnicas complementares e (c) proposta multimétodos qualitativos (ARANTES; DEUSDARÁ, 2017, p. 799).

11 Sobre o contato prévio com os participantes, tínhamos contato com um docente do Instituto pesquisado. Essa aproximação permitiu que a autorização para a geração dos dados da pesquisa fosse submetida para análise no respectivo colegiado. Cada participante assinou um termo de consentimento livre e esclarecido em que foi assegurado o sigilo da identidade e a leitura da transcrição dos dados.
} 


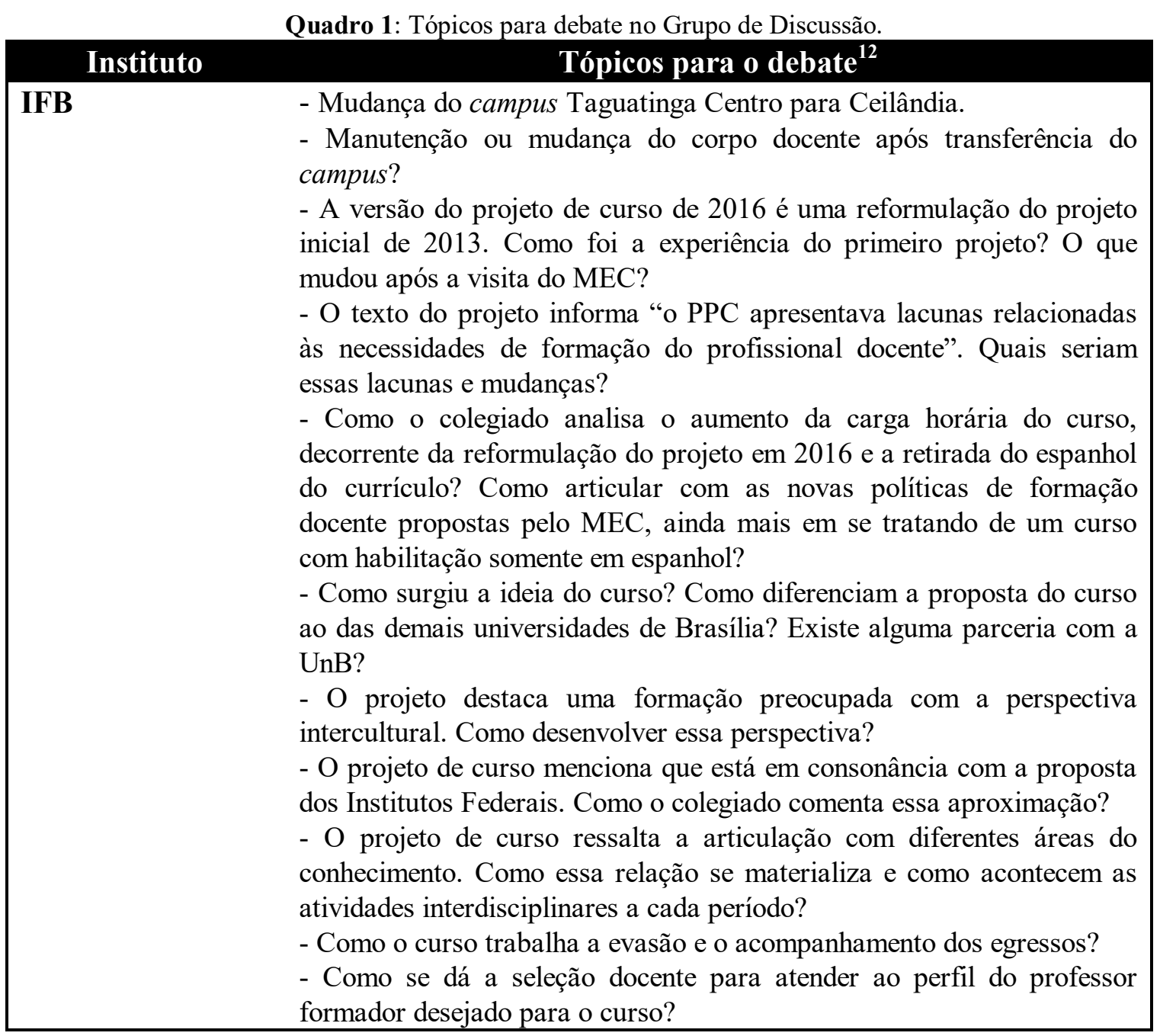

Fonte: Elaborado pelos autores.

Considerando que o roteiro poderia resultar cansativo para os participantes, optamos por agrupar algumas questões de forma a dar conta dos eixos centrais de nosso debate e do interesse da pesquisa: inserção do curso de Licenciatura no IF, contratação de professores formadores e concepções do projeto. De acordo com Arantes e Deusdará (2017, p.802), "não será a quantidade de perguntas feitas em interação que determinará a suficiência ou pertinência dos 'dados' produzidos".

Nossa perspectiva teórica de pesquisa narrativa opta por não impor uma única forma de leitura dos dados. Empregamos a composição de sentidos proposta por Telles (2002) em que o pesquisador propõe a elaboração de novas narrativas a partir das trocas experienciais e do resultado desses diálogos assim como a percepção de crenças, metáforas ou imagens que podem possibilitar a identificação de traços e características dos sujeitos participantes de uma pesquisa narrativa.

\footnotetext{
${ }^{12}$ Como já justificado, a escolha dos assuntos para debate no GD partiu das dúvidas e/ou lacunas de leitura do projeto pedagógico dos cursos, sendo que selecionamos a versão avaliada pelo MEC. Vale a pena informar que o curso recebeu a nota máxima na avaliação in loco, visita que considera as instalações físicas, corpo docente e teor da proposta pedagógica do projeto. Os participantes só tomaram conhecimento dos temas no ato da realização do grupo. Apesar de a redação de alguns tópicos constar como perguntas diretas, o debate se deu com a leitura de temas ou contextualização das questões.
} 
Dos tópicos propostos no GD, nos limitamos a compor sentidos na etapa de análise para os debates sobre três temas mais evidentes nos dados: a inserção dos cursos de Letras/Espanhol nos IFs, a contratação dos professores formadores e as mudanças de concepção do projeto, por entendermos que esses são os tópicos que mais diretamente se relacionam com os objetivos que estabelecemos na pesquisa.

O GD ocorreu em março de 2018 e contou com a participação de dois professores de língua inglesa, um da área de pedagogia e cinco da área de espanhol ${ }^{13}$. A colaboração de docentes de outras áreas foi devido à vivência deles na implementação ou coordenação do curso, o que consideramos relevante para a pesquisa por garantir pontos de vista diversos. Apesar de ser característica do GD dar o mesmo espaço de fala para todos os participantes, percebemos que no IFB a interação foi centralizada em dois docentes com maior tempo de vivência na instituição. O fato de o GD ter contado com a presença de muitos professores, fatores como timidez e silenciamento foram observados na postura das participantes recém-concursadas.

Após a realização dos GD, iniciamos a etapa de transcrição dos dados e revisão da autoria das falas como procedimentos importantes para a sistematização e nova aproximação ao material documental antes da análise dos dados. Por uma questão de opção metodológica, os participantes também receberam uma cópia da transcrição por meio eletrônico da interação ocorrida no GD.

A seguir, reconstruímos detalhes do GD e dos colaboradores. Não é nosso interesse comparar experiências entre os docentes do Instituto, mas sim compilar suas imagens do trabalho que vem sendo realizado no âmbito da formação de professores de espanhol no IFB.

\section{O projeto de curso da Licenciatura do IFB em debate: falas dos professores formadores}

Conforme exposto, optamos por realizar um GD com docentes do curso de Licenciatura do IFB com o intuito de socializar as experiências de formação de professores e verificar concepções de trabalho seguidas pelos participantes. Não foi nosso interesse no GD dar destaque individual para cada docente ou demonstrar o relato de cada um isoladamente, mas sim evidenciar as vivências do coletivo e oferecer exemplos de falas de diferentes sujeitos para a compreensão do recorte temático proposto para a leitura dos dados.

Como uma das professoras de inglês atuante na implementação do curso só poderia participar rapidamente do GD, o pesquisador iniciou pelo tópico da abertura do curso de Licenciatura em Espanhol pelo IFB. A docente informou que a primeira versão do projeto foi apresentada no final de 2012 e seu início, após aprovação nos Conselhos, ocorreu em 2013 já com a atuação de dois professores efetivos de espanhol. Diferentemente dos primeiros cursos de Letras no contexto tecnológico investigados por Silva Júnior (2016), cujas propostas eram oriundas do desejo acadêmico dos respectivos colegiados, a participante da área de educação (P1) esclareceu que no IFB a demanda surgiu da Reitoria:

13 O GD gerado em Brasília aconteceu em visita do pesquisador ao campus do referido Instituto e, embora tivesse a duração aproximada de apenas uma hora e meia, um dos docentes participante só pôde permanecer durante a discussão de um dos tópicos propostos por motivo de compromissos institucionais. 
Havia três campi que estavam sendo analisados porque eles tinham essa intenção de abrir uma licenciatura. Por que especificamente línguas? A gente tinha um documento da Secretaria de Educação que indicava que existia uma carência de profissionais na área de Matemática, Física e Línguas, sendo elas, o Inglês, o Espanhol e o Francês. A carência era muito grande de professores nessa área. Aí nós fizemos uma pesquisa [...] para visualizar as universidades que tinham em volta, quais cursos de licenciatura eles ofereciam. E a gente observou que tinha muito de Inglês, tinha muito de Português, mas só tinha uma que, à época, com Espanhol e não estava com matrículas abertas. Daí, isso foi levado para votação e o grupo optou, então, por escolher a língua espanhola. Essa foi a fundamentação que a gente teve para escolher o espanhol no antigo campus Taguatinga Centro. (P1).

A história do IFB como Instituto Federal é recente e com isso a exigência de abertura de cursos de Licenciatura para o devido atendimento da Lei de criação dessas instituições. Por isso, também se compreende a pesquisa de mercado e a análise das faculdades e universidades da região para o levantamento da demanda local. A professora destacou o pedido da Secretaria da Educação do Distrito Federal que deve ter se pautado nos dados do Censo da Educação para a apresentação das carências. A participante fez alusão ao campus de Taguatinga Centro como antigo, porque ele foi extinto e transferido para a cidade de Recanto das Emas, localidade mais distante. Com isso, os servidores puderam propor uma nova localidade para a oferta. O campus Ceilândia foi escolhido pela Reitoria porque não ministrava nenhum curso superior e já contava com espaço físico e infraestrutura adequada para recebê-lo.

O pesquisador levantou uma dúvida a respeito da transferência ou mudança do corpo docente atuante na licenciatura e a professora da área pedagógica e anterior coordenadora do curso expressou seu ponto de vista:

Foi uma transição que eu considero muito tranquila. Os professores do curso que tinham interesse em acompanhar o curso puderam vir removidos para Ceilândia sem nenhuma grande burocracia de edital. Nós viemos acompanhando o curso. O corpo docente não veio integralmente, nesse momento, alguns professores, que tinham interesse na proposta pedagógica que ia ser implantada no Recanto das Emas, acompanharam o campus. Outros já tinham interesse de trabalhar em outros campi do IFB, mais próximos da sua residência ou por outras questões, foram para esses outros campi. Num primeiro momento, veio um número significativo de professores do corpo docente para Ceilândia. Então não houve um choque tão grande em relação ao corpo docente para os estudantes. Agora, na virada para 2018, nós tivemos uma mudança significativa de corpo docente com o novo concurso. (P1).

O debate sobre o tema da mudança de campus foi decorrente de nossa preocupação com a continuidade das linhas de trabalho do corpo docente anterior e da provável desistência ou abandono de curso pelos alunos, que tiveram sua rotina modificada. Por meio da fala da professora fica evidente que a transferência de campus resultou em uma alteração das práticas pedagógicas. Por outro lado, representou um 
crescimento quantitativo do corpo docente, pois o curso recebeu mais professores e passou a assumir uma "nova identidade em relação à docência" (P1). O quadro de espanhol aumentou de quatro para sete docentes atuando na Licenciatura e um deles também colaborando no Ensino Médio Integrado. Sobre a nova constituição do colegiado, a professora expressou:

Enquanto nós estivemos em Taguatinga [...] a gente tocava o curso
com quatro docentes de espanhol. Eles tinham que se revezar nas
disciplinas. Aí todas as dificuldades que um professor tem na primeira
vez que está numa Graduação, a primeira vez que oferta uma
disciplina. A cada semestre você tem que oferecer uma disciplina nova,
porque a ideia era que você ia pegar a disciplina anterior e mais uma
nova. Isso foi se repetindo ao longo do curso. Nesse momento, eu
considero que a gente tem outro quadro. Os professores vão poder se
dedicar mais às disciplinas que se especializaram nesse semestre. Eu
considero que isso faz toda a diferença quando você consegue reeditar a
disciplina mais de uma vez. (P1).

Como o concurso de seleção de professor para o IF não pode por lei requerer titulação, nem acaba sendo direcionado para um determinado nível de ensino ou subárea de especialização, a fala da participante demonstra uma preocupação do colegiado em possibilitar que se crie identificação e divisão entre os docentes por temas e assuntos de seu interesse. Um dos professores e coordenador do curso à época mencionou que essa proposta de divisão de disciplinas por professores especialistas permite um maior trabalho integrado entre a equipe e a criação de projetos de pesquisa e/ou extensão mais articulados.

O pesquisador questionou se o concurso para o IFB já direcionava o conteúdo programático para o curso de Licenciatura ou se era um certame diferente. Leve-se em consideração que o concurso para o IFB é um dos poucos no cenário da Rede Federal de Educação Profissional que requisita somente a habilitação em Espanhol. Os participantes esclareceram que a instituição realiza uma única seleção e a escolha do campus ocorre de acordo com a classificação do candidato. Contudo, o curso de Licenciatura em Espanhol determina como pré-requisito a titulação mínima de Pós-Graduação para os candidatos interessados no campus de Ceilândia. O corpo docente não tem autonomia e não participa, diretamente, do processo seletivo para contratação de professor efetivo, pois uma empresa terceirizada é selecionada para gerir o processo. Com isso, nem sempre os pontos da prova escrita do concurso são discutidos entre os professores do IFB, por outro lado, os pontos da prova didática são mais negociáveis. Contudo, os interessados em atuar na banca devem se submeter a um edital da própria empresa:

[...] se você for contemplado dentro desse edital, você vai elaborar os pontos da prova didática e participar da banca. Especificamente, nesse último concurso, as duas professoras de espanhol do curso de Letras participaram da prova didática. Mas porque elas se predispuseram a fazer isso? Porque viram a importância das docentes do curso estarem presentes nesse momento, uma vez que, quem fosse aprovado viria a atuar no curso. (P1). 
A participação de duas professoras naquele concurso marca também uma postura política desse colegiado e sua preocupação com o perfil de docentes selecionados para o IFB e, em particular, suas competências acadêmicas para atuação na Graduação. O pesquisador indagou se muitos aprovados no certame têm o entusiasmo de atuar na Licenciatura e nos surpreendemos com as afirmações de uma das professoras, pois, segundo ela: "Da mesma forma que a gente tem docente que tem interesse em atuar na Graduação, a gente tem o inverso. A gente tem professores que não têm nenhum interesse em atuar na Graduação". (P2). A referida participante não explica os prováveis motivos da não adesão de alguns concursados ao curso de Licenciatura, mas acreditamos que não seja a falta da titulação mínima demandada. Por outro lado, outra colaboradora constatou o interesse da comunidade acadêmica por lecionar no Instituto e a mudança do perfil docente que pretende ingressar na instituição: "Nesse último concurso, até porque o Instituto Federal passou a ser mais conhecido, mais divulgado, ele atraiu outro perfil de candidato. Hoje, a gente tem, nos primeiros lugares, mestres e doutores." (P1).

Sobre a concepção de trabalho com a linguagem do projeto de curso, sabíamos que a mudança de campus e do colegiado poderia não revelar uma visão única de trabalho, mesmo porque os participantes ainda estavam se conhecendo e iniciando uma parceria no momento da geração do GD. Quando o pesquisador destacou a perspectiva intercultural de formação dos alunos e o trabalho interdisciplinar, vertentes protagonizadas no projeto de curso, os participantes acabaram omitindo o tema sobre as concepções de linguagem. Essa omissão talvez possa ser atribuída ao fato de se tratar de um assunto que, de certa forma, gere desconforto ou que precise ser mais aprofundado por parte de alguns docentes formadores. Por outro lado, os colaboradores exemplificaram também mais experiências de integração entre disciplinas ou conteúdos:

Nós, da área de Literatura, fazemos muita coisa juntos. A gente promove atividades culturais e apresentações. Por exemplo, teve atividade de ensino e poesia. Eu e a outra professora que saiu pedimos uma resenha única para as duas disciplinas. A gente procura fazer as coisas mais integradas. (P2).

Eu senti que, realmente, existe uma integração entre nós professores [...] eu peguei a disciplina de História e Aspectos Fonéticos da Língua Espanhola e eu propus, nesse primeiro momento, que o professor de História, que ele entrou agora, falar sobre a formação da Península Ibérica, os povos, o Império Romano, toda essa formação da Península e da língua. (P3).

O pesquisador também indagou a respeito do contato com a Universidade de Brasília (UnB) e a parceria entre as instituições. Os sujeitos informaram que, aos poucos, a UnB foi tomando ciência do curso, porque muitos professores do IFB são egressos dos seus programas de Pós-Graduação. Conforme algumas participantes, muitos docentes da UnB demonstram curiosidade no tocante ao currículo da Licenciatura do Instituto. Segundo a professora da área pedagógica, as instituições começaram a fazer atividades conjuntas e a aproximação ainda está mais voltada entre o corpo docente; já entre os estudantes não acontece muito. Em nossa avaliação, percebemos uma aproximação 
muito maior do IFB à UnB. Quando questionados sobre diferenças entre os cursos e/ ou contextos de atuação, uma professora teceu a seguinte distinção:

Acho que posso falar porque fui aluna da Universidade na Graduação e acho que teve uma mudança agora, recente, no currículo da UnB. A diferença maior, mesmo com essa mudança, é porque o aluno daqui pode chegar sem pré-requisito, sem nunca ter estudado espanhol, que ele vai ter esse apoio até os últimos semestres [...] na UnB, só temos três semestres que é Teoria Oral e Prática da Língua Espanhola. Aqui eles têm esse apoio ao longo do curso inteiro. (P2).

O apoio ao qual a participante se refere seria uma maior ênfase na formação para o trabalho com a aquisição da língua espanhola. Ao verificar a carga horária total do curso do IFB, notamos que a matriz totaliza 3.848 horas, sendo 1.306 dedicadas ao ensino de língua espanhola e suas literaturas, 1.542 para disciplinas da área pedagógica e recorrentes no curso de Letras, 400 de prática como componente curricular, 400 de estágio curricular supervisionado e 200 de atividades complementares. $\mathrm{O}$ fato de o curso ser de habilitação única explica a expressiva carga destinada à língua espanhola. A parte específica do curso divide-se em componentes curriculares de língua espanhola, história dos aspectos fonéticos da língua espanhola, morfossintaxe do espanhol, sociolinguística do espanhol, literatura espanhola, literatura hispano-americana e tópicos especiais no ensino de espanhol. Cada disciplina de literatura consta em três períodos do curso e identificamos outras disciplinas como Linguística Aplicada, Metodologia do Ensino, Novas Tecnologias na Educação e Gramática Comparada que podem acabar sendo direcionadas para o espanhol, implicando uma revisão da carga horária informada anteriormente. $\mathrm{O}$ acadêmico ainda pode frequentar dois componentes optativos.

Ao questionar se as disciplinas de língua espanhola também se direcionavam para o debate sobre formação docente, os professores ocultaram esse tópico. Acreditamos que essa articulação ainda seja complexa de ser discutida em se tratando de um curso recente e que sofreu uma mudança em seu quadro docente, impossibilitando, possivelmente, uma maior interação entre seu corpo social. Os participantes destacaram o envolvimento do aluno com os grupos de pesquisa, sendo essa uma atividade forte no curso, pois o corpo docente solicita trabalhos que são transformados em artigos e oficinas em eventos da área.

No entanto, no tópico sobre a reforma curricular após a avaliação do curso pelo MEC, depreendemos de forma mais clara a concepção de trabalho com as disciplinas de língua espanhola. Somente uma professora da área de educação do atual colegiado do curso teve a oportunidade de participar da implantação e reforma do projeto pedagógico. Ressalta-se que duas professoras de espanhol colaboraram nessas etapas, sendo que uma acabou sendo redistribuída para outro Instituto e a outra não seguiu atuando no campus Ceilândia. De acordo com a docente da área pedagógica, a reforma curricular permitiu colocar em prática uma nova concepção de formação:

A partir do terceiro semestre de curso, a gente já tem uma mudança significativa na grade [...] a alteração que eu considero mais drástica, digamos assim, em termos de concepção pedagógica, foi a retirada das práticas de ensino como componentes isolados e colocar essa prática de ensino de forma integrada aos componentes curriculares. Então, a ideia de que a formação docente e essa aquisição da língua iam acontecer de 
forma concomitante. Não tinha como fazer isso de forma separada: uma coisa é a formação docente outra é a língua espanhola. Como se isso não pudesse acontecer de forma concomitante. Essa foi a grande alteração que aconteceu no PPC da primeira versão para a segunda versão. (P1).

O relato da participante demonstra que o atual corpo docente tende a relacionar melhor os conteúdos e aproveitar o espaço das aulas de língua espanhola para a discussão de temas a respeito da formação de professores dessa língua. Para isso, os docentes colaboradores informaram que foi preciso ampliar um pouco a carga horária do curso.

Sobre a representação dos alunos entre o Instituto e a Universidade, a docente da área pedagógica chamou a atenção para alguns casos de desistência do curso, ainda no campus Taguatinga, porque os discentes não se identificavam com a estrutura do Instituto, pois, segundo ela:

O estudante, quando chega à Graduação, chega com uma ideia de espaço físico de universidade. Como nós não tínhamos um campus, era um andar alugado, a impressão que eles tinham era de que estavam chegando a um cursinho [...] A maioria que desistiu das primeiras turmas desistia pela falta de sentimento de pertencimento ao Instituto Federal, naquela estrutura de campus. (P1).

Os sujeitos também pontuaram a respeito do trabalho de acompanhamento de discentes no IFB, principalmente no primeiro período, como uma política interventiva para apoiar, ouvir, auxiliar na organização de tarefas e elaboração de planos de estudo. Do nosso ponto de vista, essa intervenção, aparentemente, pode ser uma preocupação muito próxima à experiência vivida com os alunos secundaristas, porém, demonstra um cuidado do corpo docente com a necessidade de promover nos acadêmicos uma caminhada mais autônoma.

O último tópico problematizado no GD foi o cenário atual do ensino de espanhol no Brasil depois da revogação da Lei $n^{0}$ 11.161/05 (BRASIL, 2005) e as consequências disso para a formação de professores. O pesquisador tinha como interesse saber as ações encabeçadas pelo Instituto na motivação dos acadêmicos e as alternativas pensadas pelo colegiado na luta pela permanência do espanhol no currículo. Um professor de língua inglesa demonstrou sua preocupação, já que nada disso foi discutido com cautela e informou, ainda, que os alunos da última entrada já chegaram nervosos e questionando o rumo. De acordo com esse participante:

Os docentes estavam meio divididos entre entrar em pânico, junto com os alunos ou tentar acalmá-los. No sentido que é uma reforma que está sendo proposta agora e a gente não sabe qual vai ser, de fato, em médio prazo. Até porque, daqui a pouco, pode entrar outro governo e ter outra política. Então, a gente tentou, na medida do possível, tranquilizar os alunos [...] a gente está começando a pensar como demanda, também, do campus em abrir uma complementação pedagógica para que os alunos consigam tirar uma segunda habilitação, paralelamente ou após a conclusão [...] poder oferecer outro leque de opções para eles. A 
gente notou a questão de Português ou Libras, que são duas possibilidades factíveis a eles. (P4).

A fala do professor demonstra a surpresa com que todos docentes e pesquisadores recebemos as notícias da Lei no 13.415/17 (BRASIL, 2017), mas sinalizou alternativas como a complementação pedagógica de modo a inserir os alunos no mercado profissional. O professor também pontuou que apesar de a língua espanhola não ser mais obrigatória, muitas escolas ainda pretendem ofertá-la. Outra professora mencionou que o governo atual caminha na contramão da Constituição Federal em seu quarto artigo que defende uma integração política, econômica e cultural entre os países latino-americanos e isso deve passar pela língua. Uma professora apontou que essa retirada é mais uma das contradições desse governo, pois:

O próprio governo que tirou o espanhol da grade do ensino médio é o governo que agora está pedindo espanhol na prova para o concurso da Agência Brasileira de Inteligência [...] Também tem a Câmara Legislativa e o Senado que também cobram o espanhol como disciplina obrigatória. (P5).

Essa mesma participante também recém-concursada expressou sua felicidade ao chegar e encontrar os alunos tão bem informados e preocupados com os rumos do ensino de espanhol na atualidade. Essa realidade fez com que ela se sentisse na obrigação de continuar motivando os estudantes e pensar o futuro para o ensino dessa língua e exemplificar novas formas de atuação como a elaboração de materiais didáticos para cursinhos ou a preparação de vídeo aulas. Por último, outra participante ressaltou que a língua espanhola será disciplina optativa na matriz do Ensino Médio integrado que recém começava no IFB, sendo que a ideia inicial era sua oferta como matéria obrigatória.

Julgamos que a aplicação do GD como instrumento foi bastante proveitosa para conhecer como os professores se expressam coletivamente sobre questões que interferem e dependem, de fato, de uma construção coletiva. Nosso interesse não era medir a performance particular de cada um dos professores atuantes no curso, mas sim verificar como as vivências e experiências relatadas colaboram para a revisitação de práticas e a formulação de novas concepções de trabalho com a formação de professores de espanhol no IFB.

\section{Considerações finais}

Neste artigo, nosso objetivo foi o de historicizar, brevemente, o processo de implantação dos cursos de Letras/Espanhol nos IFs e as experiências docentes decorrentes do projeto de curso e trabalho no IFB. Para isso, optamos por compreender o gênero projeto pedagógico e adotar o GD como instrumento para geração de dados com os professores atuantes ou com vivências no curso de Licenciatura. Concordamos com a visão de Dourado (2016) sobre a contribuição da última reforma curricular para o ensino superior brasileiro, pois essa legislação aponta a necessidade de elaboração de um projeto institucional para seus cursos de Licenciatura e nesse aspecto os IFs têm muito a contribuir para a mudança desse cenário.

Nosso processo de análise dos dados baseou-se na estratégia de composição de sentidos (TELLES, 2002), em que não buscamos comparar os relatos dos participantes, 
mas construir relações entre as vivências e as memórias resgatadas pelos sujeitosparticipantes para a compreensão de nosso objeto de pesquisa. Portanto, apresentamos nossa compreensão para o trabalho do professor formador do IFB por meio das falas geradas, que acabaram por demonstrar também um pouco de como as experiências formativas e de vida dos participantes se relacionam e contribuem para o trabalho desenvolvido no IF e na formação de novos professores de espanhol na conjuntura atual que diminui a importância dessa língua estrangeira no cenário da Educação Básica.

Os professores participantes no GD enxergaram o projeto de curso como uma prescrição que pode e deve ser ressignificada na prática diária. Um exemplo disso é a própria noção de concepção de linguagem. O projeto pesquisado não se restringe a uma única linha de trabalho, porém propõe uma perspectiva de contato com os diferentes usos sociais e a defesa por uma prática intercultural. Em parte esse discurso se materializa nos relatos sobre o trabalho com o ensino de língua espanhola e suas literaturas, contudo, uma abordagem comunicativa é mais destacada como identidade metodológica para as disciplinas de aquisição.

Durante o GD, mesmo tendo o espaço de fala para problematizar sua prática e questões relacionadas ao trabalho no Instituto, observamos que os participantes de língua espanhola pouco tomaram a palavra diretamente. Quem protagonizou o GD acabou sendo uma professora da área de educação que já tinha assumido a função de coordenação do curso e participado da implantação da Licenciatura. Talvez os demais participantes ainda não se sentissem tão à vontade para discutir os tópicos propostos pelo pesquisador, já que tínhamos a presença de docentes recém-ingressantes e outros um pouco mais antigos no Instituto (apesar do pouco tempo de atuação no campus Ceilândia). Percebemos que algumas participantes não se expressavam verbalmente, mas se olhavam entre si, exteriorizavam dúvida e, em algumas ocasiões, pareciam concordar com o dito.

Acreditamos no poder do GD como instrumento de produção de material documental que possui o papel de compreender processos de construção da realidade de interesse do pesquisador (GATTI, 2012) e também de contribuir para que os participantes ganhem maior intimidade com o pesquisador e com os próprios colegas na situação de pensar o trabalho docente. Em nosso artigo, o papel foi de refletir sobre o Instituto como local de formação de professores e de pensar práticas com a língua espanhola em um cenário de incertezas das políticas educacionais vigentes. Avaliamos como positiva a contribuição do GD para a produção de sentidos e trocas entre o pesquisador e os participantes sobre os projetos de curso e, principalmente, o trabalho realizado pelos docentes.

Para concluir, conforme comentado nas páginas antecedentes, os dados demonstraram que os IFs são instituições de ensino superior diferenciadas dos modelos já existentes na sociedade brasileira. No tocante à formação de professores, os IFs desenharam seus cursos propondo maior articulação com a Educação Básica, presente em sua proposta verticalizada de ensino, e promovendo maior integração entre os docentes e os componentes curriculares. As falas dos professores sinalizaram a vontade de crescimento da área de Letras nesses espaços originalmente do campo de ciências industriais e da natureza. A pouca experiência dos participantes como docentes de um curso de Licenciatura em Letras não implica algo negativo, porque essa lacuna possibilita a construção de caminhos e o resgate de memórias de formação do passado que podem ser positivas para fomentar as Licenciaturas nos IFs. 


\section{Referências}

ARANTES, P.; DEUSDARÁ, B. Grupo focal e prática de pesquisa em Análise do Discurso: metodologia em perspectiva dialógica. Revista de Estudos da Linguagem, Belo Horizonte, v.25, n.2, p. 791-814, 2017.

BONFIM, M. I. (coord.). A formação docente nos centros federais de educação tecnológica: diagnóstico sobre a oferta das licenciaturas nos CEFETS. Brasília: MEC/SETEC, 2004.

BRASIL. Resolução CNE/CP 1, de 18 de fevereiro de 2002. 2002a. Institui Diretrizes Curriculares Nacionais para a Formação de Professores da Educação Básica, em nível superior, curso de licenciatura, de graduação plena. CNE. Resolução CNE/CP 1/2002. Diário Oficial da União, Brasília, 9 de abril de 2002. Seção 1, p. 31. Republicada por ter saído com incorreção do original no D.O.U. de 4 de março de 2002. Seção 1, p. 8.

Resolução CNE/CP 2, de 19 de fevereiro de 2002. 2002b. Institui a duração e a carga horária dos cursos de licenciatura, de graduação plena, deformação de professores da Educação Básica em nível superior. CNE. Resolução CNE/CP2/2002. Diário Oficial da União, Brasília, 4 de março de 2002. Seção 1, p. 9.

Lei $n^{o} 11.161$, de 5 de agosto de 2005. Dispõe sobre o ensino da língua espanhola.

Lei $n^{\circ} 11.892$, de 29 de dezembro de 2008. Institui a Rede Federal de Educação Profissional Científica e Tecnológica e dá outras providências. Diário Oficial [da] República Federativa do Brasil, Poder Executivo. Brasília, DF, 30 dez. 2008, Seção 1, p. 1.

Resolução CNE/CP 2/2015, de $1^{\circ}$ de julho de 2015. Define as Diretrizes Curriculares Nacionais para a formação inicial em nível superior (cursos de licenciatura, cursos de formação pedagógica para graduados e cursos de segunda licenciatura) e para a formação continuada.

. Lei $n^{\circ}$ 13.415, de 16 de fevereiro de 2017. Altera as Leis $n^{\circ}$ 9.394, de 20 de dezembro de 1996, que estabelece as diretrizes e bases da educação nacional, e 11.494, de 20 de junho de 2007, que regulamenta o Fundo de Manutenção e Desenvolvimento da Educação Básica e de Valorização dos Profissionais da Educação, a Consolidação das Leis do Trabalho - CLT, aprovada pelo Decreto-Lei n ${ }^{\circ} 5.452$, de 1 de maio de 1943, e o Decreto-Lei $\mathrm{n}^{\mathrm{o}} 236$, de 28 de fevereiro de 1967; revoga a Lei $\mathrm{n}^{\circ} 11.161$, de 5 de agosto de 2005; e institui a Política de Fomento à Implementação de Escolas de Ensino Médio em Tempo Integral. Diário Oficial da União. Brasília, 17 de fevereiro de 2017. Seção 1, p. 1.

DOURADO, L. F. Formação de profissionais do magistério da educação básica: novas diretrizes e perspectivas. Comunicação \& Educação, v. I, p. 27-39, 2016.

FRANCO, M. S. D. P.; MOROSINI, M. C. Marcos Regulatórios e arquiteturas acadêmicas na expansão da educação superior brasileira: movimentos indutores. Revista Educação em Questão. UFRN, Programa de Pós-Graduação em Educação, Natal, RN: EDUFRN, v. 42, n. 28, p. 175-198, jan./abr, 2012.

GATTI, B. Grupo focal na pesquisa em Ciências sociais e humanas. Brasília: Liber Livro Editora, 2012. 
IF BRASÍLIA. Projeto Pedagógico do curso de Licenciatura em Letras Espanhol. 2016.

MACEDO, J. M. A mundialização do capital e seus reflexos nas politicas de formação de professores no período 1990-2010. 2011. 494p. Tese (Doutorado em Educação), Universidade Federal Fluminense, Niterói-RJ.

MARIANI, B.; MEDEIROS, V. Disciplinarização dos estudos em Análise do Discurso. Gragoatá, Niterói, n. 34, p. 15-25, jan.-jun, 2013.

OTRANTO, C. R. Criação e implantação dos Institutos Federais de Educação, Ciência e Tecnologia - IFETs. Revista Retta, v. 1, n. 1, Seropédica, RJ, p. 89-108, jan/jun, 2010.

A reforma da educação profissional e seus reflexos na educação superior. Revista Temas em Educação, v. 22, n. 2, João Pessoa, p. 122-135, jul-dez, 2013.

OTRANTO, C. R.; PAIVA, L.D.C. Contextos identitários dos Institutos Federais no Brasil: implicações da expansão da educação superior. Educação e Fronteiras On-Line, Dourados/MS, v. 6 n.16, p.07-20, jan./abr, 2016.

PACHECO, E. M. Os Institutos Federais: uma revolução na educação profissional e tecnológica. Natal: IFRN, 2010.

PEREIRA, L. A. C. A formação de professores e a capacitação de trabalhadores da Educação Profissional e Tecnológica. In: INEP/MEC. Arquivos. Brasília, 2004.

SILVA JÚNIOR, A. F. Cursos Superiores da área de Linguagens no cenário dos Institutos Federais de Educação, Ciência e Tecnologia. Anais Colóquio Internacional Educação, Cidadania e Exclusão: didática e avaliação. Campina Grande: Realize, v. 1. p. 1-12, 2015.

Cursos de Licenciatura em Letras/Espanhol nos Institutos Federais: percurso histórico e narrativas de professores formadores. In: SILVA JÚNIOR, A.F.; SANTOS, R.C. (Orgs.). Retratos de cursos de Licenciatura em Letras/ Português-Espanhol. Curitiba: Editora Appris, 2016, p. 39-149.

SIQUEIRA, A. C. Organismos internacionais, gastos sociais e reforma universitária do Governo Lula. In: NEVES, L.M.W. (Org.). Reforma universitária do Governo Lula: reflexões para o debate. São Paulo, SP: Xamã, 2004, p. 47-72.

TELLES, J. A. A trajetória narrativa: histórias sobre a prática pedagógica e a formação do professor de línguas. In: GIMENEZ, T. (org.) Trajetórias na formação de professores de línguas. Londrina: Editora UEL, 2002, p. 15-38.

VEIGA, I.P.A. Projeto político pedagógico da escola: Uma construção coletiva. In: (Org.) Projeto político-pedagógico da escola: Uma construção possível. $13^{\mathrm{a}} \overline{\mathrm{ed}}$. Campinas: Papirus, 2001, p. 11-35.

VIEIRA-ABRAHÃO, M. H. Teoria e prática na formação pré-serviço do professor de língua estrangeira. In: GIMENEZ, Telma (org.). Trajetórias na formação de professores de línguas. Londrina: Ed. UEL, 2002, p. 59-78.

Recebido em 30 de maio de 22020

Aceito em 15 de junho de 2020 